ISSN: 2379-2922

\title{
Spirtual Care Competence - Nurses Perspective
}

\author{
Mr. Ibrahim Mubarak Al Baalharith ${ }^{1}$, Dr. Ester Mary Pappiya ${ }^{2}$, Mr. Hamad Salem Al Grad ${ }^{3}$ \\ ${ }^{1}$ Regional Nursing Director, Regional Nursing Administration, Directorate of General Health Affair, Najran, \\ Saudi Arabia. \\ ${ }^{2}$ Regional Nursing Administration, Directorate of General Health Affair, Najran, Saudi Arabia. \\ ${ }^{3}$ Head of Nursing Care Regional Nursing Administration, Directorate of General Health Affair, Najran, Saudi \\ Arabia. \\ easterbala@gmail.com
}

\begin{abstract}
Background of the study: Spiritual care has recognized as part of holistic nursing care in promoting health and well-being. A holistic approach encourages the nurses to address all the physical, mental, emotional, spiritual and social needs of the patient by providing a complete model of care.Aim:To investigate the nurse's perceptive on spiritual care competence. Materials and Methods: Cross-sectional descriptive design was used to describe the perceptive of nurses on spiritual care competency at selected hospitals in Najran. Conveniencesampling technique with 100 samples and the data was obtained through the spiritual care competence scale (SCCS) and a demographic questionnaire. Data were analysed by descriptive and inferential statistics using SPSS statistical package. Results:The results showed that the mean score for the nurse's perceptive on spiritual care competence was 67.6 that indicates that the nurses were average in providing spiritual care competency. The highest score was related to attitude towards patient spirituality mean, that is, 22.43 with SD 0.57 and the lowest score was related to communication domain that is, 10.6 with 0.68 standard deviation. Conclusion: The research findings suggest that the perceptive of nurses on spiritual care competency is average and they have to pay attention to the patient spiritual care to improve their spiritual needs.
\end{abstract}

Keywords: Spiritual care, competence, perspective, nurses

\section{INTRODUCTION}

Spirituality is the nature of human life that gives meaning to life and provides hope to live ${ }^{1 .}$ Spiritual care is an emotionally sensitive, empathetic care of human spirit and not specific to religion ${ }^{2}$. The World Health The organization stated that health care needs include physical, mental, social and spiritual needs and also defined as the ability to experience the religious and ethical believes ${ }^{3}$. Spiritual care is part of holistic nursing care in promoting health and well-being ${ }^{4}$. The term spirituality and religion have different meanings. Religion is considered as a particular set of beliefs in an organized group and spirituality is considered a personal feeling of peace, purpose, and believes about life. ${ }^{6}$

Spiritual needs can be completely non-religious or incorporated with religious believes. The patient's spiritual needs are religious in nature. Spiritual needs are consisting of more than religious worship are highly individual for each patient. ${ }^{7}$ Spirituality increases the coping strategy of an individual against diseases improves the recovery and reduction of disease relapse decreases the symptoms of depression and improves the quality of life $8,9,10$. Nurses need to focus on providing spiritual care needs to the patients. Spiritual dimensions have a considerable effect on different aspects of human life and one of the responsibilities of the nurses. ${ }^{11}$

Nurses has to understand the specific skills in spiritual care dimension ${ }^{12}$. Spiritual competencies are a set of skills such as attentive listening, communication, empathy, and reassurance ${ }^{13,14}$ and need to be competent enough to identify the spiritual competencies that will improve the patient-centered care ${ }^{15}$. Many research studies have been conducted on various aspects of spirituality and spiritual training program among the nurses 


\section{Spirtual Care Competence - Nurses Perspective}

and pointing out the need to improve on the spiritual care aspects. The International Council of Nurses reported that the nurses have to meet the holistic nursing care to the clients and considered to be unethical if it is not met, ${ }^{16}$ and the American Nurses Association has integrated the spiritual care program in their baccalaureate education to promote the spiritual dimension of the care.

An online the survey was conducted among nurses in the United Kingdom revealed that $95 \%$ of nurses are encountering patients with their basic needs and reported that $5.3 \%$ of nurses were able to meet the spiritual needs ${ }^{18}$. Similarly, another study reported that the nurses did not meet the patients from diverse ethnic backgrounds spiritual needs and they were busy with their regular routine work ${ }^{19,20}$. Nurse's perception of spiritual care influence with their ability to understand the perception of spirituality before assessing the spiritual needs of others has to be encouraged ${ }^{21}$. With the background hence the investigator felt the need to conduct the study aimed to determine the nurse's perspective on spiritual care competency.

\section{Materials AND Methods}

A cross-sectional descriptive design was adopted to describe the perceptive of nurses on spiritual care competency among the nurses. The study was conducted at the Ministry of Health Hospitals in Najran. The investigator conducted a survey to collect the date and to obtain basic information to view their perceptive of spiritual care. The investigator explained the study and obtained informed consent from the participants. The samples who included in the study were all the registered nurses working under the Ministry of Health hospitals, both genders and willing to participate. All registered nurses who met the inclusion criteria and agreed to participate received an information sheet. At first, the four hospitals under the ministry of health in Najran city was selected by using a random sampling technique and to determine the sample size consisted of 100 registered nurses. Then, the nurses who were voluntarily willing to participate in the study were selected through the convenience sampling technique. The data was obtained through the spiritual care competence scale (SCCS) and a demographic questionnaire. The researcher met the majority of registered nurses who were available in various departments at the proposed hospitals during the data collection period and invited them to participate in the study. After 10 days, the researcher returned to take backfilled questionnaires. Confidentiality and anonymity in handling the data were assured throughout the study period. There was no consequence loss for their regular work and all the staff continued their routine work. Data were analyzed by descriptive and inferential statistics using SPSS statistical package.

\section{RESULTS}

Table:1 Describe the demographic characteristic of the participants were expressed. The present study findings observed that around $43 \%$ of the participants were in the age group of 25-35years and the majority of them were female and the majority of the participants were single. More than $64 \%$ of the participants were bachelor's degree and $46 \%$ of them were Indian. Regarding the experience, the majority of them belongs 1- 5 years and with the position, $68 \%$ of the participants were staff nurse. More than $76 \%$ of the participants were not aware of the spiritual care competency.

Table: 2 explained the response of nurses to the spiritual care competence scale: Mean and the standard deviation were used to express the score. The questionnaire had 27 scores and a maximum of 135.64 is low spiritual competence, 64-98 indicates average spiritual care, and above 98 shows high spiritual competence. Most of the nurses who participated in the study have an average score. Regarding attitude towards patient spirituality mean score was 22.43 with SD 0.57 which has the highest score among all the domains and regarding the communication domain mean score was 10.6 with 0.68 standard deviations has got a lower score among all the domains. In relation to the assessment and implementation of the spiritual needs, the mean score was 20.4 and the referral means the score was 12.6. Regarding the personal support and patient counselling, the mean score was 20.28 with 0.74 standard deviation, which indicated that the nurses are competent in providing 


\section{Spirtual Care Competence - Nurses Perspective}

counselling to patients in their day-to-day practice. In relation to professionalization and improving the quality of professional care, the mean score was 22.8 and overall the spiritual care competency score was 67.6, which indicates that the nurses were average in providing the spiritual care competency.

Table1. Frequency and percentage distribution of the demographic characteristic of the participants

\begin{tabular}{|c|c|c|c|c|}
\hline Variable & Category & Frequency & Percentage & P Value \\
\hline \multirow[t]{4}{*}{ Age } & $25-35$ & 43 & $43 \%$ & \multirow[t]{4}{*}{0.002} \\
\hline & $36-45$ & 34 & $34 \%$ & \\
\hline & $46-55$ & 12 & $12 \%$ & \\
\hline & $56-65$ & 11 & $11 \%$ & \\
\hline \multirow[t]{2}{*}{ Gender } & Female & 88 & $88 \%$ & \multirow[t]{2}{*}{0.052} \\
\hline & Male & 12 & $12 \%$ & \\
\hline \multirow[t]{2}{*}{ Marital status } & Single & 58 & $58 \%$ & \multirow[t]{2}{*}{0.033} \\
\hline & Married & 42 & $42 \%$ & \\
\hline \multirow[t]{3}{*}{ Professional Qualification } & Diploma & 32 & $32 \%$ & \multirow[t]{3}{*}{0.151} \\
\hline & Bachelor & 64 & $64 \%$ & \\
\hline & Masters & 04 & $4 \%$ & \\
\hline \multirow[t]{4}{*}{ Nationality } & Saudi & 12 & $12 \%$ & \multirow[t]{4}{*}{0.062} \\
\hline & Indian & 46 & $46 \%$ & \\
\hline & Pilipino & 34 & $34 \%$ & \\
\hline & others & 08 & $8 \%$ & \\
\hline \multirow[t]{3}{*}{ Experience } & $1-5$ years & 64 & $64 \%$ & \multirow[t]{3}{*}{0.523} \\
\hline & $6-15$ years & 24 & $24 \%$ & \\
\hline & More than 15 years & 12 & $12 \%$ & \\
\hline \multirow[t]{3}{*}{ Position } & Staff Nurse & 68 & $68 \%$ & \multirow[t]{3}{*}{0.036} \\
\hline & Head Nurse & 18 & $18 \%$ & \\
\hline & Supervisor & 14 & $14 \%$ & \\
\hline \multirow{2}{*}{$\begin{array}{l}\text { Aware about the spiritual } \\
\text { care competency }\end{array}$} & Yes & 24 & $24 \%$ & \multirow[t]{2}{*}{0.002} \\
\hline & No & 76 & $76 \%$ & \\
\hline
\end{tabular}

Table2. Mean and standard deviation of the nurse's response to Spiritual care competence scale

\begin{tabular}{|c|c|c|}
\hline $\begin{array}{c}\text { Spiritual care Competence } \\
\text { Domain }\end{array}$ & Mean & Standard Deviation \\
\hline Attitude towards patient Spirituality & 22.43 & 0.57 \\
\hline Communication & 10.6 & 0.18 \\
\hline Assessment & 20.4 & 0.68 \\
\hline Referral & 12.6 & 0.26 \\
\hline Counselling & 20.28 & 0.74 \\
\hline Professionalism & 22.8 & 0.56 \\
\hline $\begin{array}{c}\text { Evaluation of the spiritual Care Competency } \\
\text { of nurses }\end{array}$ & 67.6 & 1.86 \\
\hline
\end{tabular}


Spirtual Care Competence - Nurses Perspective

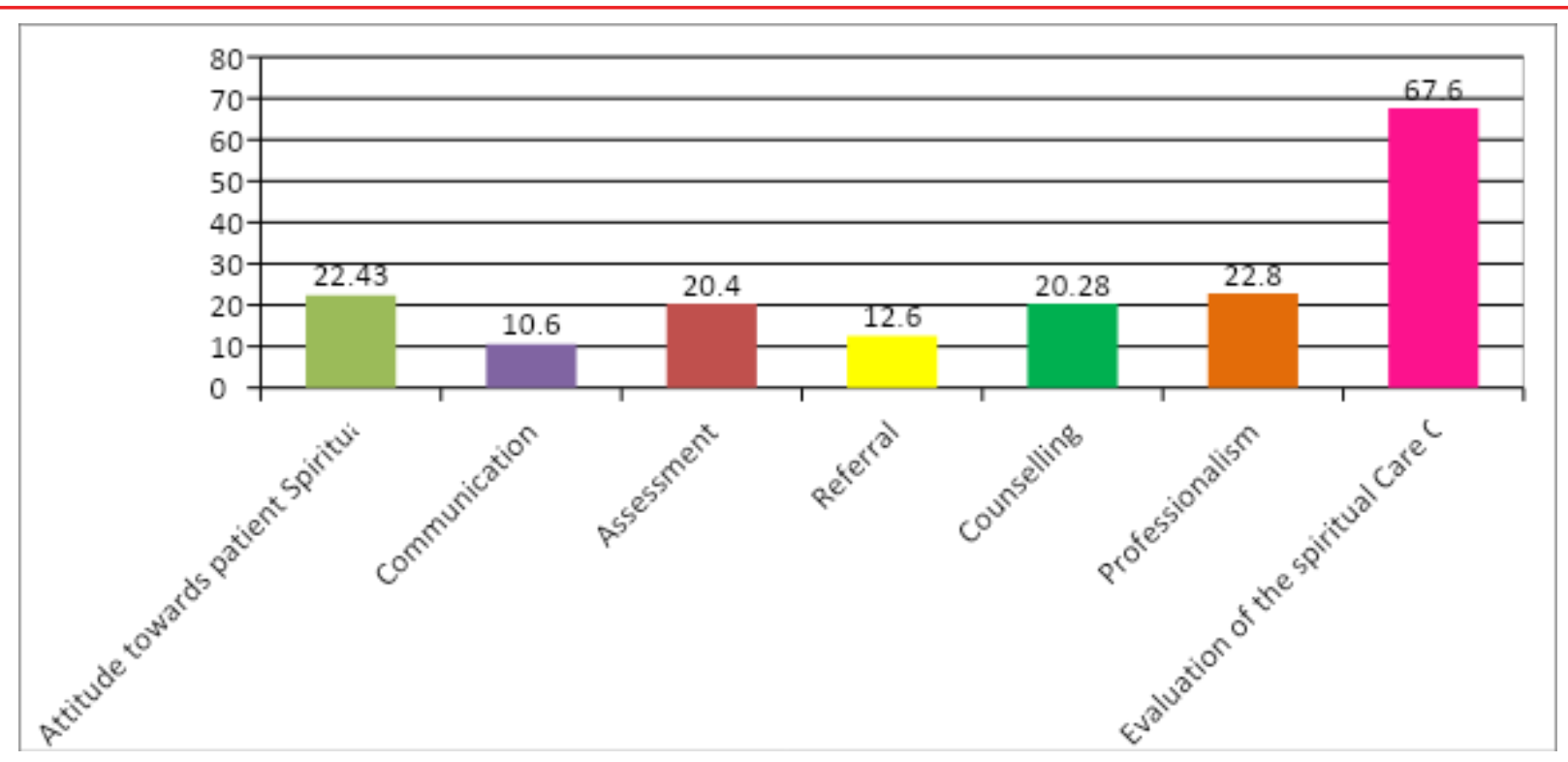

Fig1. Mean Score of the nurse's response to Spiritual Care Competence scale

\section{DiscuSSION}

Spiritual care promotes spiritual well-being of the patients and it's necessary to consider the importance of spiritual care on individual health ${ }^{22}$. The present study analysed the perceptive of the nurses on spiritual care competency in Najran and revealed that the majority of the nurse's perception on spiritual care competence was average. Adib-Hajbagheryetal conducted a study on nurse's competency in providing spiritual care among nurses in Iran and the results reported that the nurses were competent in proving spiritual care ${ }^{23}$. The present study findings reported that the highest score obtained towards the attitude of the patient spirituality domain, which indicates that the nurses were busy with regular routine work and they do respect rituals, values, cultural beliefs, and customs of their patients. The results were supported by Won get al conducted a study to assess the level of knowledge on spirituality among nurses and reported that the nurses had an adequate level of understanding and awareness of spirituality and great interest in providing spiritual care to their patients ${ }^{24}$. Similarly another study reported that nurses maintain a trusty relationship with patients while addressing their spiritual needs.The present study findings reported that the communication domain has got a lower score in all the domains and most of the nurses reported that they were much busy with their regular routine work and do not find sufficient time to communicate with patients related to their spiritual needs. Baldacchino conducted a study on nursing, competencies among senior nursing students and reported that the communication domain has a low score and emphasized that communication skills need to be improved among the senior nurses while meeting the spiritualneeds ${ }^{25}$. Similarly, another study reported that nurses were comprehensive in meeting the physical needs and poor in meeting the spiritual needs ${ }^{26}$. The present study reported that the perceptive of providing spiritual care competencies were very limited among nurses. The researcher has also studied other aspects of spirituality and spiritual care and only limited studies focused on the spiritual care competencies. A descriptive study was conducted among nurses on the perception of spiritual care and reported that there was in assessing spiritual needs ${ }^{27}$. Similarly, an exploratory research study was conducted on spirituality and provision of spiritual care among nurses working at PICU and the results revealed that there was a positive significance in identifying the spiritual needs among the nurses ${ }^{29}$. The nurse's perception of spirituality can influence their attitude and behaviour and it is important to understand their own perception of spirituality before assessing the spiritual needs of others. There are certain limitations in this study was it was assessed only 
the perceptive of the spiritual care competence among the nurses in Najran. The results are not generalizable to the large population of the nurses and a small number of participants participated in the study. Therefore, the study will be strengthened if could have some training program on spiritual care competency in the future; the interventional study can be focused on large samples

\section{CONCLUSION}

The research findings suggest that the perceptive of nurses on spiritual care competency is average and they have to pay attention to spiritual care to improve the spiritual needs of the patients. However, according to the study findings, it is necessary to emphasize the spiritual care competency-training program for the nurses in health care settings.

\section{Acknowledgement}

The authors would like to thank all the nurses participating in this research study.

\section{REFERENCES}

1. Wilding, C. (2007) Spirituality as sustenance for mental health and meaningful doing: a case illustration. Medical Journal of Australia; 186: S67-69.

2. Claire J, Creutzfeldt., Robert G, Holloway and Melanie, Walker. (2012). Symptomatic and palliative care for stroke survivors. Journal of General Internal Medicine, 27 (7), 853-860.

3. World Health Organization report on Spirituality and spiritual health 2011.

4. Gaur KL, Sharma, M. (2014). Measuring spiritual health: Spiritual Health Assessment Scale (SHAS), International Journal of Innovative Research and development, 3 (3), 63-67.

5. Selimen D, Andsoy II. The importance of a holistic approach during the perioperative period. AORN journal. 2011; 93(4):482-90. DOI: 10.1016/j.aorn.2010.09.029.

6. Shahrabadi R, Masroor D, Hadjizadeh S, Hosseini F. Comparison of the attitudes of the last year nursing and medical students about spiritual care. Cardiovascular Nurse J 2012; 1:30-3.

7. Satori P (2010). Spirituality 1: should spiritual and religious beliefs be part of patient care? Nursing Times; 106: 28.

8. Tazakori Z, Valizade S, Mohammed E, Hasankhani H. Process of spiritual care learning in Iranian Nursing. J Nurse Midwifery Uremic University Med Science 2013; 11:51-63.

9. Kristelle JL, Rhodes M, Crape LD, Sheets V. Oncologist Assisted Spiritual Intervention Study (OASIS): patient acceptability and initial evidence of effects. The International Journal of Psychiatry in Medicine. 2005 35(4):329-47. DOI: 10.2190/8AE4-F01C-60M0-85C8 10.

10. Balboni T, M, Paulk ME, Phelps A, Wright A, Petit J, et al. Support of cancer patients' spiritual needs and associations with medical care costs at the end of life. Cancer. 2011; 117(23):5383- 91. DOI: 10.1002/ cncr.26221.

11. Salmani F, Azarbarzin M, Mohammed M. The relationship between spiritual health and life expectancy in patients with cancer. Aflac 2008; 4:41-9.

12. Royal College of nursing (2011), RCN Spirituality in Nursing Care: A pocket Guide.RCN, London, 1-9.

13. Fallahikhoshknab M, Maher M. Spirituality, Spiritual Care and Spiritual Therapy. Tehran: University of Social Welfare and Rehabilitation Sciences Publication; 2008. 
14. Meretoja R, Isiah H, Leino-Kilpi H. Nurse competence scale: Development and psychometric testing. J Adv. Nurse 2004; 47:124-33.

15. Van Leeuwen R, Tiesinga LJ, Middle B, Post D, Jochemsen H. The validity and reliability of an instrument to assess nursing competencies in spiritual care. J Clinical Nurse 2009; 18:2857-69.

16. International council of nurses. (2014), Code of ethics for nurses. Geneva, Switzerland, 1-4.

17. American Nurses Association (2014), spiritual care in the scope and standards of nursing practice.

18. Balboni, TA et al (2007) Religious and spiritual support among advanced cancer patients and associations with end-of-life treatment preferences and quality of life. Journal of Clinical Oncology; 25: 5, 555-560.

19. Timmins F., Neill F., Kelly, John. (2014), Spiritual Dimensions of care: Developing an educational package for hospital nurses in the Republic of Ireland. Holistic Nursing practice, March/April, 106-124.

20. Hilbert, J., Haynes, A.S \& kiviak, J.G (2010). Spirituality and health: An exploratory study of hospital patients' perspectives. Australian Health Review, 34 (1), 3-10.

21. Dhamani KA, Paul P, Olson JK. Tanzanian nurses understanding and practice of spiritual care. ISRN Nurse 2011; 2011:534803.

22. Mainguy B, Valenti Pickren M, Mehl-Madrona L. Relationships between level of spiritual transformation and medical outcome. Adv Mind Body Med 2013; 27:4-11.

23. Adib-Hajbaghery M, Zehtabchi S, Fini IA. Iranian nurses' professional competence spiritual care in 2014. Nursing Ethics.2017:24:462-73.

24. Wong KF, Lee LY, Lee JK. Hong Kong enrolled nurses' perceptions of spirituality and spiritual care. Int Nurs Rev. 2008; 55:333-40.

25. Baldacchino DR. Nursing competencies for spiritual care. J Clinical Nurse. 2006; 15:885-96.

26. Pesut $B$, author. The development of nursing students' spirituality and spiritual care giving. Nurse Education Today. 2002; 22:128-35.

27. Owens J, authors. A critical incident study of nurses' responses to the spiritual needs of their patients. Advance Nurse. 2001; 33:446-55.

28. Nascimento LC., et al. (2016), Spiritual care: The nurses' experiences in the pediatric intensive care units, Religion, 7 (3), 174-184

Citation: Mr. Ibrahim Mubarak Al Baalharith, Dr. Ester Mary Pappiya, Mr. Hamad Salem Al Grad, "Spirtual Care Competence - Nurses Perspective". American Research Journal of Nursing. 2020; 6(1): 1-6.

Copyright (C) 2020 Mr. Ibrahim Mubarak Al Baalharith, Dr. Ester Mary Pappiya, Mr. Hamad Salem Al Grad, This is an open access article distributed under the Creative Commons Attribution License, which permits unrestricted use, distribution, and reproduction in any medium, provided the original work is properly cited. 